\title{
The effects of liveweight, and of the quality of the feed given previously, on the ad libitum intakes of a poor quality hay by sheep of 5 breeds of different mature liveweights
}

\author{
GC Emmans, NC Friggens
}

\section{SAC, Genetics and Behavioural Sciences, Bush Estate, Penicuik, Scotland, UK}

Systems exist to predict the daily rate at which a sheep will eat a particular food. In these, it is conventional to describe the sheep only by some function of it's liveweight, W. Such systems predict that sheep of breeds with different values of mature liveweight $(A)$, will, at the same $W$, have the same daily rate of food intake. There is no reason a priori why this should be so, but there is little experimental evidence for or against. On high quality foods, which do not constrain the rate of intake through their bulk, there are reasons (Emmans et al, 1987, Animal Production, 44, 476) for expecting intake, at a given $W$, to differ between sheep of different $A$. The purpose of the work described here was to measure the intakes of a poor quality hay $(H)$ at different values of $W$ for sheep of breeds with a range of values of $A$. The effect of the quality of the food given until, and between, the tests on the intake of $\mathrm{H}$ was also measured.

Entire males of five breeds of sheep of different A were used. The same 8 individuals of each breed were tested at each of 3 values of $W$. The table shows the values of $W$ and the estimates of $A$ for each breed which were Welsh Mountain (WM), Scottish Blackface (SB), Greek Karagouniko (GK), Shetland (SH) and Suffolk (SF). Half of the sheep of each breed were fed ad libitum from weaning on either a pelleted concentrated food, C, (196 g CP and 12.5 MJ ME per $\mathrm{kg} \mathrm{DM}$ ) or on chopped alfalfa hay, $F,(181 \mathrm{~g} \mathrm{CP}$ and 9.0 MJ ME per $\mathrm{kg} \mathrm{DM})$, except for the three 28-day test periods. The test food was a chopped hay, $\mathrm{H},(880 \mathrm{~g} \mathrm{DM} / \mathrm{kg}$; $86 \mathrm{~g} \mathrm{CP}$ and $6.2 \mathrm{MJ} \mathrm{ME} \mathrm{per} \mathrm{kg}$ DM) of poor quality. The sheep were kept in single pens.

The daily rate of intake of hay increased with time within the 28 day test periods, although weight change was essentially zero. The overall mean intakes were $320,512,568$ and 631 (se 18) $\mathrm{g} / \mathrm{d}$ in the four successive weeks averaged over all other factors. Intake of $\mathrm{H}$ was higher, even in week 4 of the tests, for the sheep previously fed on $F$ than in those previously fed on C : $700 \vee 563$ (sed 30), g/d. The main effects of breed and test on intake $\mathrm{g} / \mathrm{d}$, and the weights at test, $\mathrm{kg}$, are shown in the table.

Intakes in week 4 of each test were used and are shown in the table. Between tests 1 and 2 liveweights increased; in test 2 they were 1.45 times as great as in test 1 . Intakes also increased in proportion so that in test 2 they were 1.49 (se 0.077) times as great as in test 1. However, while liveweights increased between tests 2 and 3 so that they were 1.63 times as great in test 3 as in test 2, intakes hardly changed and were only 1.01 (se 0.044) times as great in test 3 as in test 2. The data thus show that there was no simple relationship between liveweight and the rate of intake of the limiting food, $\mathrm{H}$, as the sheep grew. The Suffolk, the breed with the greatest mature size, had the lowest proportional intake ( $\mathrm{g} / \mathrm{kg}$ liveweight day) of all of the breeds in all tests.

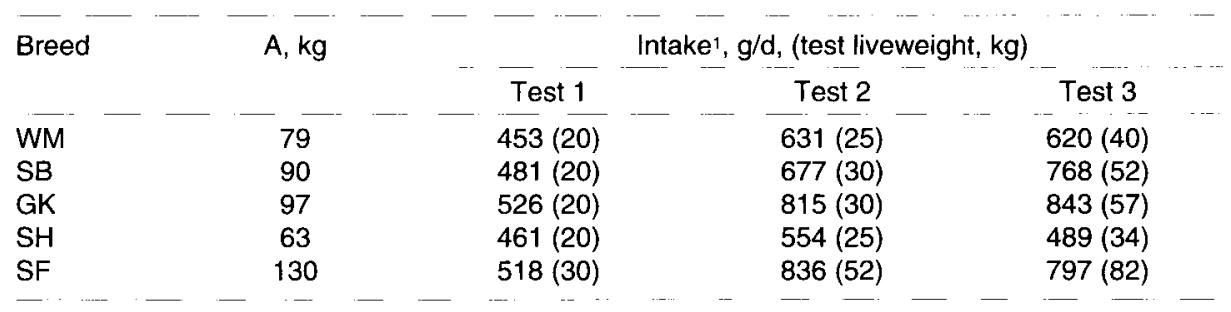

1 mean standard error of each daily intake was $\pm 59 \mathrm{~g} / \mathrm{d}$ 